\title{
Improved bit error rate evaluation of M-ary DPPM modulation using an aperture averaging for FSO systems impaired by interchannel crosstalk and ASE noise
}

Ebrahim E. Elsayed ( $\nabla$ engebrahem16@gmail.com )

Mansoura University Faculty of Engineering https://orcid.org/0000-0002-7208-2194

\section{Research Article}

Keywords: Amplified spontaneous emission, Pointing error, Digital pulse position modulation, Free-space optical communication, Modified Chernoff bound, Aperture-averaging

Posted Date: April 14th, 2021

DOl: https://doi.org/10.21203/rs.3.rs-347173/v1

License: (9) This work is licensed under a Creative Commons Attribution 4.0 International License. Read Full License 


\section{Abstract}

The performance evaluation of free-space optical (FSO) communication system using the digital pulse position modulation (DPPM) and on-off keying non-return-to-zero (OOK-NRZ) approach are investigated in this paper. The impact of atmospheric turbulence, scintillation and amplified spontaneous emission (ASE) noise has been taken into account. To reduce the turbulence-induced scintillation and optical power penalty, the use aperture averaging has been proposed in this paper. To evaluate the bit-error rate (BER) performance in the presence the atmospheric turbulence and amplified spontaneous emission (ASE), the use of the moment generation function techniques are explained with the modified Chernoff bound that is more accurate and an appropriate from Chernoff bound. Such a system, which could provide a power efficient, a low cost, excessive flexibility and reliable or considered a massive solution in the bandwidth provision for future access networks, and together for higher data rate. The BER, are given for an optically preamplified DPPM FSO communication system impaired by pointing error and atmospheric turbulence combined, in addition to the ASE noise arising from the optical amplification. The gamma-gamma distribution model is used to characterize the whole range of turbulence conditions. The results reveal the superiority of DPPM with improved receiver sensitivity (at a binary data rate $2.5 \mathrm{Gbps}$ and at typical FSO BER of 10-9) of about $10 \mathrm{~dB}-11 \mathrm{~dB}$ for coding level (M) of 5 and optical link length (for turbulent interaction) of $2000 \mathrm{~m}$ more than an equivalent optically preamplified OOK-NRZ approach, depending on the leve of turbulence.

\section{Full Text}

This preprint is available for download as a PDF.

\section{Figures}

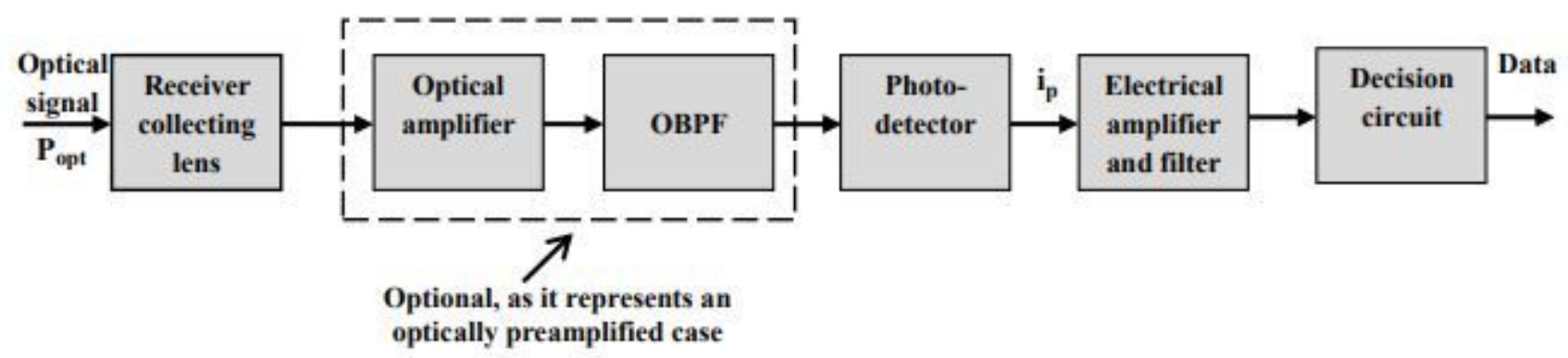

\section{Figure 1}

Block diagram of optically FSO receiver 

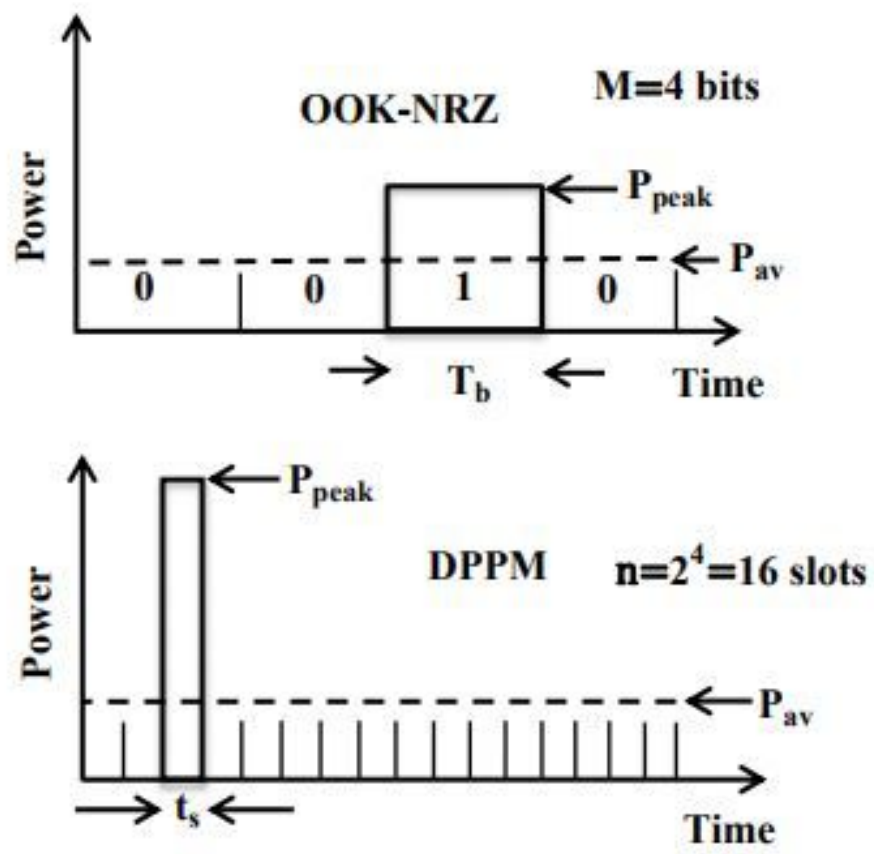

Figure 2

Illustration of OOK-NRZ and DPPM frame for $M=4$ ( $n=24=16$ slots) 

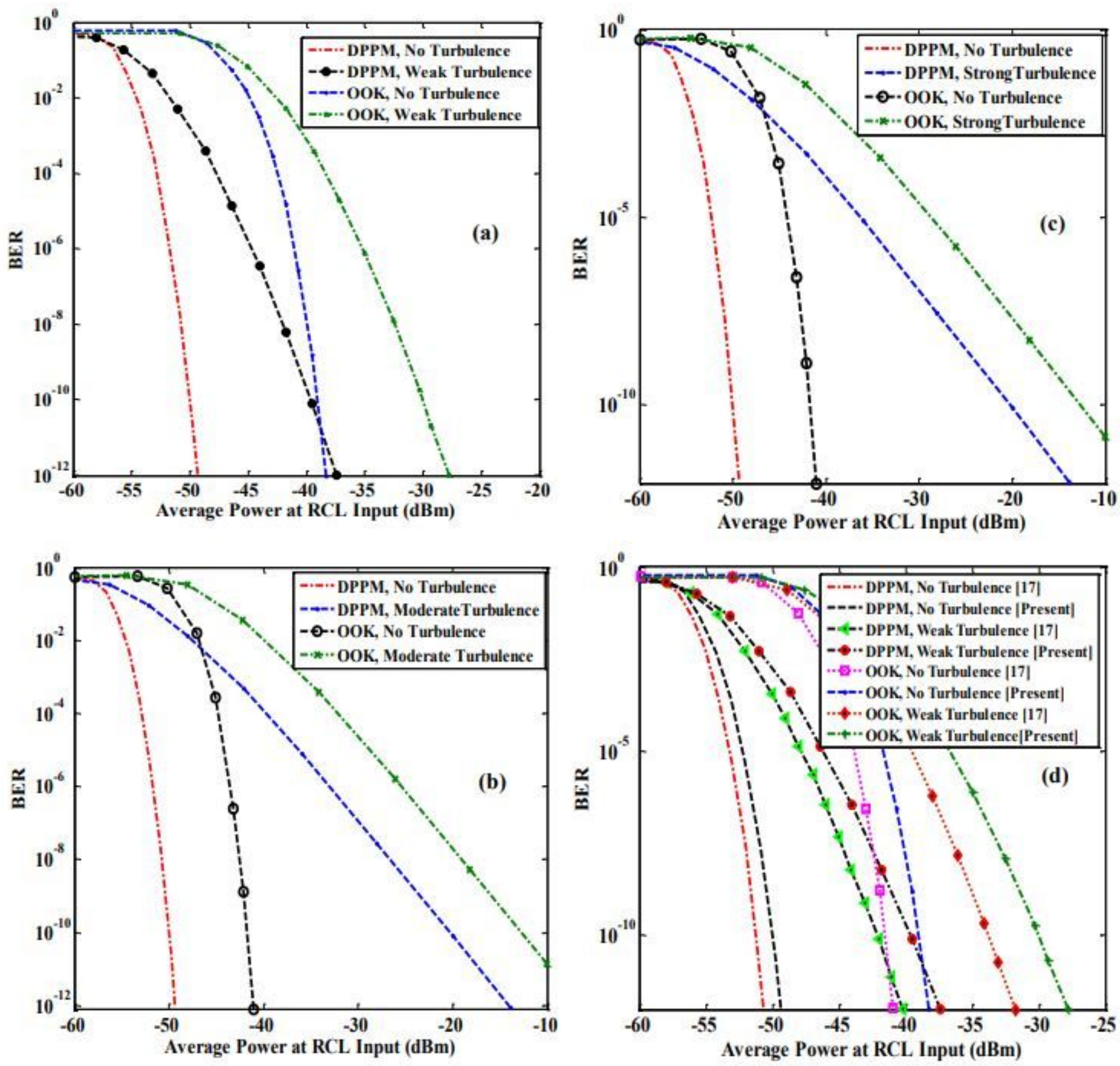

Figure 3

shows BER vs. average power at receiver collecting lens (RCL) input (dBm) for DPPM and OOK using MCB, while $M=5$, lf so= $2000 \mathrm{~m}, \mathrm{G}=30 \mathrm{~dB}$, and DRX = $25 \mathrm{~mm}$ for NT. (a) WT, (b) MT, (c) ST and (d) comparison for no turbulence and weak turbulence, that presented in [17], [present], all AA. 